\title{
Filosofia e História em Thomas Hobbes: uma leitura de An Historical Narration Concerning Heresy
}

\author{
Philosophy and History in Thomas Hobbes: a reading of An Historical \\ Narration Concerning Heresy
}

\author{
João de Azevedo e Dias Duarte \\ jadduarte@puc-rio.br \\ Professor de História Moderna \\ Pontifícia Universidade Católica do Rio de Janeiro \\ Marquês de São Vicente, 225, Edifício Cardeal Frings, Sala F512, Gávea \\ 22451-900 - Rio de Janeiro - Rio de Janeiro \\ Brasil
}

\section{Resumo}

Este artigo discute a função da história no pensamento do filósofo inglês Thomas Hobbes. A primeira parte do artigo trata da crítica de Hobbes à importância conferida à experiência e à história pela tradição clássico-humanista e de sua defesa da superioridade epistêmica da razão e da filosofia. A segunda parte concentra-se em sua obra postumamente publicada, An Historical Narration Concerning Heresy (1680), buscando interpretá-la à luz das convenções do gênero da história eclesiástica e dos debates político-religiosos do período da Restauração inglesa. Argumenta-se, finalmente, que essa obra é um tipo de história teoricamente informada, concebida para se constituir como uma intervenção retoricamente efetiva em um debate contemporâneo acerca da heresia e de sua punição e da jurisdição eclesiástica.

Thomas Hobbes, História, Filosofia.

\begin{abstract}
This article discusses the function of history in the thought of Thomas Hobbes. The first part of the article considers Hobbes's critique of the importance placed on experience and history by the classical humanist tradition, and his defense of the epistemic superiority of reason and philosophy. The second part focuses on his posthumous work An Historical Narration Concerning Heresy (1680), interpreting it in the light of ecclesiastical history genre conventions and English Restoration's political and religious debates. Finally, this study argues that this work is a kind of theoretically informed history, conceived to be a rhetorically effective intervention on a contemporary debate on heresy and its punishment, and on ecclesiastical jurisdiction.
\end{abstract}

\section{Keywords}

Thomas Hobbes; History; Philosophy. 
Normalmente ignorados pela maioria dos estudantes de seus grandes tratados sistemáticos das décadas de 1640 e 1650, os trabalhos de Hobbes do período da Restauração ${ }^{1}$ cobrem uma variedade extraordinária de gêneros e modos de escrita, tais como: diálogo, carta, panfleto, autobiografias, traduções completas da Ilíada e da Odisseia de Homero etc. Entre essas obras tardias encontram-se as três únicas histórias que Hobbes escreveu: Behemoth ou o Longo Parlamento, o relato de Hobbes sobre as guerras civis inglesa; e as menos conhecidas Historia Ecclesiastica e An Historical Narration Concerning Heresy and the Punishment Thereof. Por que Hobbes decidira em seus últimos anos experimentar tão extensamente com formas literárias é uma questão à qual, embora fascinante, não me dedicarei neste texto. É bem possível que essa decisão tenha decorrido do reconhecimento de que, sozinha, a ciência demonstrativa - i.e., a "razão" desamparada pela eloquência - seria impotente para persuadir; um reconhecimento que, de acordo com Quentin Skinner (1996), teria levado Hobbes ao seu retorno tardio à retórica e, portanto, também a modos mais imaginativos de escrita do que a árida prosa científica dos primeiros tratados. Seja como for, interessa-me mais, neste momento, investigar o tipo de história praticado por Hobbes, e minha estratégia aqui será focar numa leitura de sua breve história da heresia. Nessa leitura, buscarei levar em consideração alguns contextos, quais sejam: os comentários relativos à história e à filosofia, à experiência e à razão, contidos nos tratados anteriores de Hobbes; as convenções da História Eclesiástica, gênero no qual a narrativa de Hobbes é vazada; e os debates político-religosos da Inglaterra no século XVII, especialmente no período da Restauração, e suas articulações historiográficas. O argumento que buscarei articular neste artigo é que An Historical Narration é uma história teoricamente informada - um tipo de história filosófica ou conceitual, se quisermos -, conscientemente desenhada para intervir efetivamente em um debate contemporâneo acerca da definção de heresia, de sua punição e da hierarquia relativa entre Estado e Igreja.

\section{História e filosofia}

Embora Hobbes tenha escrito histórias apenas em suas últimas décadas de vida, desde cedo em sua carreira, interessou-se ativamente pela quarta das disciplinas humanistas, o estudo da história, como é possível verificar em suas autobiografias (cf. SKINNER 1996, p. 235). Com efeito, a primeira publicação de Hobbes, em 1629, foi uma tradução erudita do original grego para o inglês da História da Guerra do Peloponeso de Tucídides (Eight bookes of the Peloponnesian Warre). É interessante notar que as razões aduzidas por Hobbes para traduzir e publicar o trabalho do historiador grego foram, conforme apontado por Skinner, "de um tipo eminentemente humanista", i.e., pragmáticas e didáticas (SKINNER 1996, p. 242). ${ }^{2}$ Escrevendo no contexto deflagrado das

\footnotetext{
${ }^{1}$ Convencionalmente, o período da história política inglesa que começa com o restabelecimento da monarquia e da Igreja da Inglaterra, sob Carlos II, em 1660, e termina com a deposição de Jaime II, em 1689, na sequência da chamada "Revolução Gloriosa".

2 Salvo indicado, todas as traduções de citações neste texto são de minha autoria.
} 
disputas entre a Coroa e o Parlamento no final da década de 1620, Hobbes pretendia ensinar a seus contemporâneos a respeito dos perigos representados pela democracia e pelos seus oradores por meio do estabelecimento de uma comparação histórica entre antigos "democratas atenienses" e parlamentares modernos. Desse modo, no prefácio de sua tradução, Hobbes louva Tucídides não apenas por ter sido o historiador que "de todos menos gostava da democracia", mas também por sua habilidade de realizar melhor do que qualquer outro "o trabalho principal e próprio da história", i.e., "instruir e capacitar (enable) os homens, pelo conhecimento das ações passadas, a portarem-se prudentemente no presente e providencialmente em relação ao futuro" (apud SKINNER 1996, p. 242). Como bem notou Karl Schuhmann (2000, p. 14), "o primeiro (early) Hobbes compartilhava assim a convicção dos humanistas relativa à Historia Magistra Vitae, tal como expressa pela fórmula de Cícero". Porém, em seus trabalhos de maturidade, Hobbes expressaria uma visão muito mais cética em relação à capacidade de instrução das histórias e ao valor da prudência na vida política e moral. Isso é consistente com a hipótese de Skinner (1996, p. 250) de que "ao passo que Hobbes fora inicialmente formado pela cultura retórica do humanismo renascentista, não há dúvida de que, na década de 1630, ele começou a desertar os studia humanitatis em favor de um tipo diferente de scientia e ao mesmo tempo a reagir com veemência contra as suas afinidades (allegiances) intelectuais anteriores".

Já em seu primeiro tratado em política e direito, The Elements of Law (1640), Hobbes dedicou-se a estabelecer uma distinção entre dois tipos de conhecimento, a prudência e a sapiência. A primeira, que possui sua origem na sensação e é modelada pelas operações da memória, é um conhecimento derivado da experiência, sendo a experiência "nada mais do que a lembrança de quais antecedentes foram seguidos por quais consequências" (HOBBES apud SKINNER 1996, p. 259). A prudência implica uma habilidade para "conjecturar, pelo presente, aquilo que é passado e aquilo que é porvir" (HOBBES apud SKINNER 1996, p. 260). A ser contrastado com a prudência há, porém, um outro tipo de conhecimento: a sapiência. Embora essa também tenha seus começos na sensação (como, para Hobbes, todo o conhecimento deve ter), ela consiste não em experiência dos fatos, mas em "conhecimento da verdade das proposições, e de como as coisas são nomeadas" (HOBBES apud SKINNER 1996, p. 260). A sapiência, ou o conhecimento verdadeiro, apenas pode ser adquirida por meio daquilo que Hobbes chama "filosofia" ou "ciência", i.e., o método de derivar consequências necessárias e universais de proposições baseadas em definições inequívocas, acuradas e, portanto, confiáveis dos termos.

Uma vez estabelecida essa distinção, Hobbes prossegue, em The Elements, com um ataque à suposição que reside no coração mesmo do pensamento humanista - suposição que, como vimos, ele próprio parece ter sustentado em sua juventude: a ideia de que o estudo da história é o modo apropriado para se adquirir sabedoria em assuntos políticos e morais. Em vez de empregar a tópica humanista/ciceroniana tradicional para enaltecer a história (historia vero testis temporum, lux veritatis, vita memoriae, magistra vitae...), Hobbes 
simplesmente a define como "o registro que mantemos nos livros" a respeito "da experiência dos efeitos das coisas", acrescentando que essa experiência "nada conclui de forma universal" (HOBBES apud SKINNER 1996, p. 260). Na medida em que a sapiência requer conclusões universais, segue-se que a história não pode ser uma mestra desse tipo de sabedoria. Naturalmente, é consabido que, para o pensamento humanista, a história era uma fonte não de episteme ou sophia (conhecimento dos primeiros princípios), mas de sabedoria prática ou prudência, amiúde referida como auriga virtutum (ou "condutora das virtudes") por seu papel central e diretor em um caráter moral excelente. Ainda que Hobbes concorde que a história é uma fonte de prudência, longe de conceber a prudência em termos tão elevados, ele a trata desdenhosamente como "nada mais que conjectura a partir da experiência", não uma virtude intelectual superior, a ser cultivada por estadistas e generais, mas uma habilidade que compartilhamos com as "feras selvagens (brute beasts)" (HOBBES apud SKINNER 1996, p. 262).

Se nos voltarmos para o Leviatã, o último dos grandes tratados políticos de Hobbes, não encontraremos nenhuma mudança em sua visão sobre esses temas. A despeito de seu endosso parcial das artes retóricas, o Leviatã ainda trata a experiência com suspeição e contrasta o conhecimento dela derivado com a verdadeira sabedoria. "Assim como a muita experiência é prudência", diz Hobbes, "também a muita ciência é sapiência [...:] ambas úteis, mas apenas a segunda infalível" (Lev. 1.V; 1983, p. 31). ${ }^{3}$ Enquanto mera "suposição do futuro, tirada da experiência dos tempos passados", a prudência permanece para sempre incerta, "porque observar pela experiência e lembrar todas as circunstâncias que podem alterar o sucesso é impossível" (Lev. 1 .III e V; 1983 p. 18 e 31). O futuro, diz Hobbes, é "apenas uma ficção do espírito", que se constrói "aplicando as consequências das ações passadas às ações que são presentes, o que é feito com muita certeza por aquele que tem mais experiência, mas não com certeza suficiente" (Lev. 1.III; 1983: 18 - grifos meus). Embora seja verdade que quanto mais experientes somos, mais sábios nos tornamos em termos de capacidade de previsão prudencial, também é verdadeiro que a prudência é apenas um tipo de conhecimento "quantitativo e atuarial" (POCOCK 1989 , p. 155). A experiência pode ser acumulada indefinidamente, trazendo consigo graus de certeza cada vez maiores, sem, contudo, jamais se tornar segura. Se o conhecimento do futuro não é senão presunção - "pois a previsão das coisas que estão para vir, que é providência, só compete" a Deus, que é autor e não observador das coisas (Lev. 1.III; 1983, p. 18) -, o conhecimento do passado não é menos incerto. Tentar determinar o que pode ter acontecido numa determinada situação a partir daquilo que se observou ter acontecido em situações similares é tão presunçoso quanto tentar prever o futuro:

Pois aquele que tiver visto por que graus e fases um Estado florescente primeiro entra em guerra civil e depois chega à ruína, ao observar as ruínas de qualquer outro Estado, pressuporá uma guerra semelhante e 
fases semelhantes ali também. Mas esta conjetura tem quase a mesma incerteza que a conjetura do futuro, sendo ambas baseadas apenas na experiência (Lev. 1.III; 1983, p. 18, grifos meus).

A incerteza constitutiva da experiência é, portanto, transferida para qualquer raciocínio dela derivado, e a única maneira de suprimi-la consiste em não raciocinar de uma ocorrência passada para uma futura, ou de uma passada para outra passada, mas sim de premissa à consequência. O que equivale a separar, como bem notou John Pocock (1989, p. 157), "o mundo da consequência lógica do mundo da consequência temporal, o mundo da consequência necessária racionalmente percebida do mundo dos fatos observados pela sensação e pela memória à medida que ocorrem no tempo". Essa separação estabelece uma divisão marcada entre a história e a filosofia, entre "conhecimento dos fatos" e "conhecimento das consequências de uma afirmação para a outra" (Lev. 1.IX; 1983, p. 51). Há, porém, uma assimetria nessa dicotomia, pois a primeira jamais será conhecimento verdadeiro, para Hobbes. Afinal, diz ele, "nenhum discurso pode terminar no conhecimento absoluto dos fatos, passados ou vindouros" (Lev. 1.VII; 1983, p. 40). O único modo de conhecer é conceitual e condicionalmente, operando não "da consequência de uma coisa para a outra, e sim do nome de uma coisa a outro nome da mesma coisa" (Lev. 1.VII; 1983, p. 40). Se seguirmos corretamente os quatro passos do método científico começando com definições apropriadas das palavras, juntando-as em afirmações gerais, e essas em silogismos, até chegarmos a conclusões sólidas - lograremos verdades universais, válidas em quaisquer circunstâncias porque independentes da experiência, particular e duvidosa.

A separação estabelecida entre filosofia e história explica por que Hobbes, consistente com sua aspiração por um ciência demonstrativa da política, evita, em seus tratados sistemáticos, recorrer a fatos e exemplos extraídos da história para apoiar os seus argumentos. "Sejam quais forem os exemplos que se possa tirar da história", diz ele, no capítulo XLII do Leviatã, "esses exemplos não constituem argumentos" (Lev. 3.XLII; 1983, p. 317-318). Exemplos passados não podem decidir em questões relativas ao bem e ao mal, ou ao verdadeiro e ao falso. Na melhor das hipóteses, eles oferecem uma "probabilidade de direito", mas, no fim das contas, "exemplos não provam nada" (Lev. 3.XLII; 1983, p. 340). O mesmo princípio vale no campo do Direito - no qual a história havia se tornado, no Renascimento, uma disciplina auxiliar fundamental -, e está em pleno acordo com a crítica de Hobbes à tradição do Direito Consuetudinário. ${ }^{4} \mathrm{~A}$ juris prudentia, diz Hobbes, parafraseando o famoso jurista Sir Edward Coke, ou "aquela perfeição artificial da razão, obtida através de muito estudo, observação e experiência", não pode ser igualada ao juízo soberano e usada para ajuizar em questões de certo e errado, "pois é possível que muito estudo fortaleça

\footnotetext{
${ }^{4}$ Sobre essa tradição como um dos principais idiomas políticos na Inglaterra do século XVII, cf. Pocock (1987). Sobre a relação entre o direito consuetudinário e a história no humanismo renascentista, os trabalhos de Donald Kelley ainda são indispensáveis, cf., p. ex., Kelley (1966; 1970). Sobre Hobbes e o Direito, cf. Goldsmith (1996).
} 
e confirme sentenças errôneas, e quando se constrói sob falsos fundamentos quanto mais se constrói maior é a ruína" (Lev. 2.XXVI; 1983, p. 164). Segue-se que, em Hobbes, "nem a história nem precedente passarão [...] por lei" (EW VI, Dialogue; 1840, p. 109 apud SCHUHMANN 2000, p. 7).

Há ainda uma outra razão, ética e política, mais do que epistemológica, para diminuir a importância da história. Para Hobbes, "uma das causas mais frequentes de [rebelião contra a monarquia] é a leitura de livros de política e de história dos antigos gregos e romanos" (Lev. 2.XXIX; 1983, p. 194). Isso porque os autores desses livros (com a provável exceção de Tucídides) "em vez de fazerem derivar [os direitos do Estado] dos princípios da natureza os transcreviam para seus livros a partir da prática de seus próprios Estados, que eram populares" (Lev. 2.XXI; 1983, p. 132). Sendo a abordagem dos autores antigos baseada na experiência, e a sua experiência republicana ou "popular", segue-se eo ipso que também os seus princípios são dessa natureza. Assim, ao lerem as histórias daqueles antigos "autores democráticos", "os jovens, e todos aqueles que são desprovidos do antídoto de uma sólida razão", impressionados com as grandes façanhas narradas, absorvem inconscientemente uma falsa teoria da soberania e, ensinados a detestar a monarquia, acabam levados à sedição e à guerra civil, "com uma imensa efusão de sangue" (Lev. 2.XXIX e XXI; 1983, p. 195-196 e 132). Em resultado, "jamais uma coisa foi paga tão caro como estas partes ocidentais pagaram o aprendizado das línguas grega e latina" (Lev. 2.XXI; 1983, p. 132).

Essa última frase deixa claro que os argumentos de Hobbes contra a experiência, a prudência e a história equivalem a um ataque direto à tradição clássico-humanista. Parece correta, portanto, a conclusão de Karl Schuhmann (2000, p. 7-8) de que:

[...] em Hobbes, a arte da escrita da história perdeu a função central que havia adquirido no humanismo. Enquanto o humanismo havia exaltado a obra histórica acima da filosofia meramente conceitual em vista de sua vívida e efetiva contribuição para a vida moral, exibindo exemplos de bom e mau comportamento e expondo-nos a um teatro da ação moral e imoral - um tipo de laboratório moral - o filósofo Hobbes atém-se à [...] visão de que o conhecimento histórico permanece para sempre imperfeito porque não pode ser exaustivo. [...] Assim, o fim moral da escrita da história, que, para os humanistas, era a sua principal raison d'être, é transferido por Hobbes para a filosofia.

Não obstante, Hobbes escreveu histórias.

\section{An Historical Narration Concerning Heresy}

An Historical Narration Concerning Heresy and the Punishment Thereof foi publicada postumamente, primeiro em 1680 e, então, em 1682. No entanto, fora escrita muito antes, provavelmente na segunda metade da década de 1660, e é sabido que circulou em forma manuscrita durante os anos 1670 (CHAMPION 2007). Não tendo sido publicada durante a vida de seu autor, An Historical Narration teve o mesmo destino de suas outras duas histórias, Behemoth 
(1680) e Historia Ecclesiastica (1688) e de outros escritos contemporâneos que lidam com temas cognatos, tais como: A Dialogue between a Philosopher and a Student of the Common Laws of England (1681), An Answer to Bishop Bramhall's Book, called The Catching of the Leviathan (1682) e On the Law of Heresy. ${ }^{5}$ Esses trabalhos atestam o clima de intolerância e de perseguição religiosa vigente durante a Restauração. ${ }^{6}$ Explicando por que decidira não publicá-los, Hobbes escreveu em uma de suas autobiografias: "non sinebant tempora ut publicarentur" ("os tempos não permitiriam que fossem publicados") (Vita apud LESSAY 2000, p. 147). Restabelecida no poder, a facção realista e anglicana derrotada na guerra civil de 1640 encontrava-se, então, em uma disposição extremamente reacionária, decidida a extirpar quaisquer opiniões religiosas e políticas suspeitas, e Hobbes tornou-se um alvo favorito. Como coloca Noel Malcolm: "durante os anos 1660 e 1670, Hobbes foi frequentemente atacado, na imprensa e do púlpito, pelo seu suposto ateísmo, negação de valores morais objetivos, promoção da devassidão e assim por diante" (1996, p. 35). Essas acusações tornaram-se mais sérias, quando, em 1666, um comitê foi criado na Câmara dos Comuns para investigar livros acusados de serem heréticos, nomeando "em particular [...] o livro do Sr. Hobbs chamado O Leviatã" (apud Malcolm 1996, p. 36). Graças a um antigo decreto de Henrique IV (de Haeretico comburendo), abolido apenas em 1678, a punição prevista para a condenação por heresia ainda incluía a morte na fogueira (cf. WILLMAN 1970, p. 608; CHAMPION 2007, p. 221-222). Embora essas ameaças não tenham gerado 32 maiores consequências, Hobbes, temendo por sua vida, tomou-as seriamente.

An Historical Narration é parte de um conjunto de escritos contemporâneos nos quais Hobbes procurou defender-se publicamente, ainda que não pela imprensa, dessas acusações. A estratégia seguida, nesse texto, envolvia enfrentar os seus inimigos em seu próprio campo, o que significava, para Hobbes, não apenas tornar-se um especialista em heresia e na sua legislação, mas também verter os seus argumentos no modo usual de argumentação de seus adversários, i.e., como uma história da igreja cristã primitiva. An Historical Narration é, portanto, uma História Eclesiástica ou da Igreja (do mesmo modo que sua Historia Ecclesiastica, mais explicitamente, o é), uma bem estabelecida e muito praticada forma de historiografia na época. .

De acordo com Arnaldo Momigliano, dois elementos se destacam como características definidoras da historiografia eclesiástica: a inter-relação entre doutrina e fato, teologia e história, e o sentido transcendental atribuído às origens. "Em nenhuma outra história", diz Momigliano, "os precedentes significam tanto como na história eclesiástica [...;] na Igreja, a conformidade com as origens é prova de verdade" (2004, p. 192). Se um senso do passado, e da continuidade do presente em relação a ele, é um elemento identitário central em qualquer sociedade, isso é talvez ainda mais verdadeiro para uma sociedade cristã, dado que essa tem de se definir em termos do legado de Cristo, avaliando o presente

\footnotetext{
${ }^{5}$ Em relação a esse último trabalho, publicado apenas no século XX, cf. Mintz (1968) e Willman (1970). ${ }^{6}$ Recentemente caracterizada por um especialista como "o pior período de perseguição religiosa da história britânica" (HARRIS 2006, p. 29).
} 
segundo uma concepção desse evento histórico (e espiritual). Isso é evidente na Historia Ecclesiastica de Eusébio de Cesareia, considerada a primeira e o modelo para toda história eclesiástica subsequente. Eusébio definiu um padrão para a escrita da história da nova nação cristã e de sua igreja baseado nos pilares gêmeos da ortodoxia doutrinária e da sucessão apostólica. Sua narrativa era uma narrativa acerca do triunfo da igreja sobre a perseguição e a heresia e de sua continuidade no tempo através da sucessão dos bispos nas sés apostólicas como herdeiros legítimos de Cristo. De acordo com Momigliano, o foco de Eusébio nas noções de "heresia" - uma noção ausente tanto da historiografia judaica quanto da Bíblia (sendo mencionada apenas de passagem nos Atos dos Apóstolos) e de "sucessão" (diadoche) era tributário da historiografia pagã, em particular, dos relatos sobre as escolas gregas de filosofia (tal como encontramos em Diógenes Laércio, por exemplo). Jamais abandonado inteiramente, porém um tanto ou quanto eclipsado durante a Idade Média, o modelo eusebiano de história eclesiástica experimentou uma intensa retomada após a Reforma, sendo usado tanto por protestantes quanto por católicos romanos em suas disputas relativas a qual igreja possuía a autoridade das origens em seu favor, sendo, portanto, a única e verdadeira igreja universal de Cristo.

Se, na Inglaterra do século XVII, histórias constituíam um modo central de argumentação política7, e dada a ausência de "uma separação conceitual entre questões de Igreja e de Estado, de religião e de política" (CHAMPION 1992, p. 6), pode-se, então, dizer que histórias eclesiásticas eram um instrumento privilegiado de controvérsia. Com efeito, trabalhos recentes têm insistido no protagonismo da religião nas disputas políticas inglesas ao longo do século XVII, e mesmo do XVIII, contra a persistente tendência "whig" da historiografia de tratar a política desse período de uma perspectiva "secular".8 O padrão peculiar assumido pela Reforma na Inglaterra - um movimento desencadeado por um decreto real que, rompendo com o bispo de Roma, instituiu o Estado como suprema autoridade civil e eclesiástica - e pela Igreja anglicana - equilibrada entre elementos doutrinários e litúrgicos reformados e remanescentes da Igreja medieval - determinou os contornos das disputas subsequentes. Como coloca Justin Champion, insistindo sobre a indissociabilidade de questões teológicas, eclesiológicas e político-filosóficas nesse período, "debates sobre a natureza da soberania monárquica necessariamente cruzavam-se com discussões sobre a competência e independência da Igreja. Conformidade ao arranjo eclesiástico era análogo à obediência política, ao passo que inovações teológicas eram amiúde consideradas como uma forma de sedição secular" (CHAMPION 1992 , p. 6). De acordo com Jonathan Scott (1990, p. 110), a história política inglesa do século XVII pode ser vista como uma sequência de (três) "crises do papismo e do governo arbitrário" (1937-42, 1678-83, 1687-9), que "eram fundamentalmente sobre religião". ${ }^{9}$ O que estava em jogo nessas crises não era

\footnotetext{
7 Como demonstrou John Pocock (cf. 1987; 2003) de forma seminal em relação aos idiomas jurídicos e civis da historiografia inglesa do início da época moderna.

${ }^{8}$ Cf., p. ex., Morril (1984), Goldie et al. (1990), Champion (1992), Harris (1993; 2005; 2006) e Duarte (2017).

9 "Papismo" era um conceito polêmico, pragmaticamente flexível, que denotava práticas associadas ao
} 
apenas a ameaça representada pelo modelo do absolutismo católico continental, mas fundamentalmente a própria relação entre a Igreja e o Estado.

Durante a Restauração, o estabelecimento político-eclesiástico estava outra vez no centro dos debates, à medida que uma forma agressiva de anglicanismo, herdeira do laudianismo de 1630, lograva aos poucos impor a sua visão autoritária e excludente da Igreja, convertendo a monarquia restaurada em um intolerante Estado confessional que negava direitos religiosos e civis a boa parte da população, submetendo "dissidentes" ou "não conformistas" (como ficaram conhecidos aqueles que discordavam dos artigos de fé, liturgia e forma de governo anglicanos) a uma violenta política persecutória. As tensões entre essa visão teocrática, "High-Church", das relações entre Estado e Igreja e as demandas crescentes por compreensão, tolerância religiosa e liberdade de consciência, misturando-se e alimentando as disputas constitucionais e sucessórias, estão na base do surgimento da polaridade partidária Tories/Whigs na década de 1680. Combinando argumentos filosóficos, bíblicos e históricos, as posições ideológicas em disputa buscavam se legimitar apresentando-se não apenas como mais "racionais", mas também como mais "puras" e "ortodoxas", i.e., conformes à "verdadeira religião", o que implicava conformidade às origens. Compreende-se, portanto, o recurso frequente a histórias da Igreja. Narrativa e erudição histórico-filológica não eram meros exercícios acadêmicos, mas, sim, poderosos instrumentos de combate ideológico.

Segundo Justin Champion (1992, p. 22), um dos pontos centrais de $\mathcal{H}$ dissenção nas histórias eclesiásticas publicadas na Inglaterra no século XVII e, especialmente, no período da Restauração, era justamente aquele das "hierarquias relativas da Igreja e do Estado". Balizado pela teorização eclesiológica pós-Reforma, o campo historiográfico dividia-se entre, de um lado, aqueles que, como o historiador e polemista High-Church Peter Heylyn, em obras como Ecclesia Restaurata (1661), defendiam a independência da Igreja baseada na origem de jure divino da autoridade espiritual da hierarquia episcopal, negando a leigos e à monarquia qualquer competência teológica ou controle sobre o ritual, e, de outro, aqueles que defendiam a supremacia real e a submissão da ordem espiritual ao poder civil, como Edward Stillingfleet ou Gilbert Burnet, em obras como Irenicum (1666) ou The History of the Reformation (1679-1714), respectivamente. Ao passo que os defensores da autoridade sacerdotal de jure divino costumavam invocar o modelo da Igreja primitiva pré-Constantiniana, a concessão direta de Cristo e a sucessão apostólica a seu favor, denunciando as implicações erastianas dos argumentos de seus adversários (sua tendência a reduzir a moralidade ou verdade da religião às determinações do Estado), os defensores da supremacia real retorquiam mobilizando frequentemente os exemplos do Imperador Constantino ou de Henrique VIII, como príncipes piedosos, restauradores da "verdadeira religião" contra os desvios da idolatria, da superstição e do domínio clerical "papista".

catolicismo romano, entre as quais a tendência do clero a assumir um papel político, disputando a soberania com o poder civil. Nesse sentido, não se restringia à Igreja de Roma, sendo frequentemente imputado ao alto clero protestante, fosse ele presbiteriano ou episcopal. 
A questão da "heresia" e de sua punição tinha um lugar de destaque nesse debate. Com base na autoridade patrística, em especial de Santo Agostinho, a Igreja Romana, desde os primeiros tempos de sua conversão em religião pública, recorreu ao braço armado do poder temporal para perseguir as 'heresias' e garantir a uniformidade da doutrina e do ritual considerados 'católicos' (universais), da qual se supunha depender a unidade e estabilidade da cristandade. Rompendo essa unidade, a Reforma protestante não significou, como se poderia pensar, um abandono do ideal de uniformidade religiosa, mas, sim, a multiplicação de 'catolicismos', cujos sacerdotes recorriam aos mesmos argumentos patrísticos para dirigir a espada do príncipe piedoso contra aqueles que consideravam heréticos e apóstatas (sempre os outros). A heresia, tal como meticulosamente anatomizada por uma longa e copiosa tradição heresiográfica - compartilhada tanto por católicos romanos quanto por protestantes de diferentes matizes, e que tinha em Gangrena (1646), do presbiteriano Thomas Edwards, um célebre expoente inglês - era sinônimo de licenciosidade moral, cisma e sedição política, ao mesmo tempo uma ofensa a Deus e uma ameaça à ordem civil. ${ }^{10}$

Segundo Mark Goldie (1991), durante a Restauração, a típica posição anglicana High-Church em relação à heresia consistia na defesa veemente da punição à dissenção e na consequente recusa de quaisquer propostas de compreensão e/ou tolerância religiosa. Para isso, autores como Richard Perrinchief, em Indulgence not Justified (1668), ou Thomas Long, The History of the Donatists (1677), estabelecendo paralelos entre os não conformistas contemporâneos e os heréticos e cismáticos arianos e donatistas dos primeiros séculos, repetiam os dicta de Crisóstomo, Nazianzo, Ambrósio e, sobretudo, de Agostinho em favor da perseguição aos dissidentes. De acordo com essa visão, a Igreja (pelo que se entendia os bispos) seria a única autoridade teológica competente (porque divinamente instituída) e, portanto, responsável pela pureza doutrinária e disciplina moral, na manutenção das quais o príncipe deveria atuar apenas sob sua orientação. No campo adversário, partidários da supremacia real, separavam dissenção teológica e dissenção política, propondo esquemas de compreensão e tolerância religiosa, baseados na antiga noção de que na âmbito da prática e doutrina cristã havia muitas "coisas indiferentes" (adiaphora), não prescritas por Cristo como necessárias à salvação. Sendo, portanto, de jure humano, a definição de certas cerimônias e credos, em nome da ordem e da decência do culto público e não da salvação pessoal, seria uma prerrogativa do magistrado civil, e punições seriam injustificadas, a menos que houvesse perigo à segurança do Estado.

Seguindo o padrão habitual no século XVII, essas diferentes posições ideológicas articulavam-se através de grossos volumes consagrados ao tratamento histórico erudito de práticas e de instituições do passado judaicocristão. Longe de lhe serem um estorvo, o elã polêmico e o viés partidário dessa historiografia eram, ao contrário, um estímulo à crítica histórico-filológica. À

\footnotetext{
${ }^{10}$ Sobre a prática e racionalidade da intolerância religiosa na Europa do início da época moderna, especialmente na Inglaterra, e a persistência da identificação da heresia à pestilência, sedição, comunismo, "libertinismo" e "sodomia", cf. Marshall (2007) e Goldie (1991).
} 
medida que as posições divergentes buscavam persuadir seus leitores acerca da verdade dos seus argumentos, construindo sua autoridade textual por meio da mobilização regular de um conjunto de dispositivos eruditos de prova (citações, notas de rodapé, apêndices com transcrições de manuscritos antigos etc.), uma ideia empírica de evidência provável ou correta ganhava, cada vez mais, importância no interior da concepção humanista, ético-retórica, da história - concretizando, assim, o lento movimento, saudado pelos historiadores dos séculos XIX e XX, da antiga res gestae à moderna disciplina. ${ }^{11}$

De que modo An Historical Narration se insere nesse padrão? Claramente, Hobbes estava operando com o modelo eusebiano. Como esperado em uma história da igreja, o relato regressa ao distante passado cristão de modo a dele extrair implicações normativas para o presente. Também é mantido o padrão de tratar de forma conjunta questões doutrinárias e factuais. Assim como Eusébio, Hobbes destaca os empréstimos da igreja primitiva às escolas gregas de filosofia, embora, ao contrário do historiador romano, interessado em preservar o legado pagão no interior do cristianismo, insista em sua influência corruptora. Com efeito, An Historical Narration não é uma narrativa sobre o triunfo de uma instituição divina, com seus princípios verdadeiros e ministros puros, sobre a heresia e a perseguição, mas sim uma narrativa sobre a corrupção de uma instituição secular (nada é dito sobre a sua suposta origem divina) por uma casta sacerdotal interesseira e desejosa de poder, disposta a definir doutrinas teológicas abstrusas (não contidas nas Escrituras e derivadas das noções "absurdas" da filosofia pagã) como artigos de fé obrigatórios à salvação e a perseguir inocentes com o único objetivo de estabelecer o seu próprio domínio sobre os homens. Em relação às disputas inglesas contemporâneas, Hobbes colocava-se, assim, decididamente, no campo dos defensores da supremacia real, articulando uma posição erastiana radical, segundo a qual definições de ortodoxia e de heresia seriam meramente o resultado de convenções humanas e uma prerrogativa da autoridade civil (que intervém no campo teológico com o propósito exclusivo de garantir a paz e a ordem do corpo político), não possuindo os clérigos qualquer tipo de mandato divino para punir dissenções doutrinárias.

Há ainda um outro sentido, temático-formal, pelo qual An Historical Narration dá continuidade ao padrão contemporâneo da historiografia eclesiástica. Tratase de uma história da palavra heresia, ou, como Hobbes a descreve, "uma relação histórica relativa à palavra heresia, desde o seu primeiro uso entre os gregos até o tempo presente" (EW IV, Answer; 1840, p. 384). A etimologia - essa antiga arte praticada em obras com De Lingua Latina, de Varrão, e retomada entusiasticamente na cultura filológica humanista - desempenha um papel importante no texto de Hobbes, que procede diacronicamente, traçando a evolução dos sentidos das palavras "heresia" e "herético" por meio do exame dos seus usos em diferentes contextos sociolinguísticos. Nesse

\footnotetext{
${ }_{11}$ Para um tratamento não teleológico dessa transição na prática historiográfica no ínico da época moderna, entendida não como uma ruptura epistemológica radical, mas sim como um sutil deslocamento de ênfase, operado no interior do regime retórico, cf. Grafton (2007). Sobre a contribuição decisiva das disputas políticoreligiosas do século XVII para esse movimento, cf. Champion (1992).
} 
sentido, An Historical Narration poderia ser lida como oferecendo o que Justin Champion (2007, p. 228) chamou de "uma teoria estagiária (stadial theory) do desenvolvimento histórico da heresia" .

Isso significa que deveríamos atribuir a Hobbes algum tipo de protohistorismo, seguindo a definição de Ankersmit (1995, p. 144) do historismo como a visão de que "a natureza de uma coisa reside em sua história"? Certamente, não. A noção de caráter idealista, fundamental ao historismo em sua formulação alemã clássica, de um substrato metafísico de sentido revelando-se progressivamente através dos fenômenos históricos (mesmo na forma não anacrônica do providencialismo) seria totalmente inconsistente com o nominalismo radical de Hobbes e sua consequente rejeição de essências não materiais ou espirituais. ${ }^{12}$ Não obstante, o procedimento etimológico hobbesiano parece tornar a distinção entre filosofia e história examinada anteriormente mais flexível, apontando, assim, para um caminho mais plausível para a compreensão da prática historiográfica tardia de Hobbes: talvez, a sua desvalorização da história como forma de conhecimento, tal como habitualmente entendida pela tradição preceptiva humanista, fosse compatível com uma adesão, ao menos parcial, aos procedimentos contemporâneos da crítica erudita, histórico-filológica.

É verdade que algum tipo de diacronia, desempenha um papel naquilo que Hobbes chama filosofia ou ciência, ao menos em seu primeiro passo metodológico, aquele da definição conceitual. Embora insista que "etimologias não são definições", Hobbes concede que, "quando verdadeiras, elas dão muita luz para a descoberta de uma definição" (EW VI, Dialogue; 1840, p. 80). Com efeito, Hobbes amiúde emprega etimologias em seus tratados para chegar a definições. Por exemplo, na discussão sobre o conceito de justiça, em The Elements of Law, ele começa examinando as origens e usos dos termos "justo" e "injusto" como predicados de ações e conclui definindo "justo" como um ato feito com um direito ou ius e, vice versa, "injusto" como aquilo que é feito sine iure (cf. SKINNER 1996, p. 310).

An Historical Narration segue um procedimento similar. Uma definição de heresia é apresentada logo nas primeiras frases do texto, e de acordo com a sua etimologia: "a palavra heresia é grega e significa uma assunção de algum coisa, em particular, a assunção de uma opinião". Em sua origem, nas escolas gregas de filosofia, a heresia "não significava mais do que uma opinião privada, sem referência à verdade ou à falsidade" (EW IV, Narration; 1840, p. 387). No restante do texto, Hobbes traça uma série de mudanças histórico-semânticas experimentadas pela noção de heresia desde os primeiros séculos do cristianismo até o século XVII. Ele descreve como a noção, transposta, nos primeiros séculos, do seu contexto filosófico pagão original à igreja cristã primitiva, adquiriu um significado pejorativo na forma de uma adjetivo ("herético") oposto a outro ("católico") e aplicado a pessoas e ideias. Descreve ainda como o imperador Constantino, no intuito de conter o derramamento de sangue causado, em

\footnotetext{
12 Subscrevo a definição de nominalismo oferecida por John Pocock (1989, p. 184): "por nominalismo pode ser entendido [...] uma filosofia que afirma que nosso conhecimento é de palavras, denotando coisas que não devem ser entendidas em si mesmas".
} 
Alexandria, pelas disputas cristológicas entre Ário e Alexandre, tornou, pela primeira vez, a heresia um crime passível de punição civil no clero, ao mesmo tempo que sancionou, com sua autoridade, o primeiro credo ortodoxo (o Credo Niceno). Trata também da conversão da heresia ao mesmo tempo em um crime capital e em um pecado mortal, quando da usurpação do poder eclesiástico das mãos dos imperadores pelo Papa - um desenvolvimento, infelizmente, seguido pelas Igrejas protestantes.

No entanto, todas essas mudanças não são senão circunstanciais, na medida em que são incapazes de alterar a natureza fundamental e original da heresia que é ser "não mais do que opinião privada", como o filósofo já a havia definido, de forma clara e perspícua, no Leviatã (Lev. 1.XI; 1983, p. 63). Desta definição básica é possível deduzir algumas consequências necessárias que independem da história semântica do conceito, tais como: não há nenhum parâmetro teológico absoluto de verdade a partir do qual se possa condenar a heresia; ou essa não pode ser um crime se não representar ameaça à ordem pública. Pode-se dizer, portanto, que a definição correta da heresia, lograda com a ajuda da etimologia, e as consequências lógicas dela derivadas oferecem uma perspectiva crítica, racional, da qual é possível organizar e avaliar a sua própria história.

Nesse caso, poderíamos, então, estender à historiografia hobbesiana aquilo que Ankersmit disse a respeito da historiografia do Iluminismo de uma maneira geral: que ela é sustentada por uma "ontologia da sentença" (ontology of the statement): "a ontologia da sentença de modo algum exclui a mudança, mesmo a mudança radical. Apenas, quando a mudança ocorre, seremos sempre capazes de identificar um sujeito imutável da mudança ao qual essa pode ser imputada" (1995, p. 146). Há apenas um senão nessa caracterização: o termo "ontologia" aplica-se mal a Hobbes, pois seu nominalismo impede o corolário substancialista - que Ankersmit atribui ao Iluminismo - de que o termo-sujeito em um enunciado constativo se refere necessariamente a uma entidade na realidade extralinguística. Não obstante, a lógica proposicional, de fato, subjaz o pensamento histórico de Hobbes.

Há porém uma diferença importante entre o procedimento de Hobbes em seus tratados e em suas histórias. Ao passo que, em The Elements, uma vez definidas a justiça e a injustiça, Hobbes procede more geometrico, em An Historical Narration, ele quase nunca abandona a exposição narrativa. Isso não significa que Hobbes estivesse buscando "conhecimento dos fatos", nem no sentido de um interesse antiquário pelo passado qua passado nem no sentido de antevisão prudencial. Certo, seu interesse era prático. Ele estava, afinal de contas, intervindo em um debate relativo à heresia e a sua punição, no qual, como vimos, tinha fortes razões pessoais para se envolver. No entanto, embora sua "ansiedade pessoal o tenha incitado a prestar uma atenção mais circunstanciada à questão da natureza da heresia e de sua punição", como bem notou Champion (2007, p. 224), "também não há dúvida de que as questões nucleares relativas à relação entre opinião privada, autoridade clerical e jurisdição civil eram uma preocupação perene sua". Com efeito, as principais ideias articuladas em An Historical Narration - como, p. ex., o argumento erastiano acerca da 
impossibilidade de existirem duas jurisdições independentes (civil e eclesiástica) em um mesmo Estado ou a denúncia da enorme responsabilidade da politicagem clerical (priestcraft) ${ }^{13}$ pelos tumultos políticos em todos os tempos - também podem ser encontradas em outros textos do mesmo período, bem como nos grandes tratados anteriores. O que é diferente aqui é o modo de exposição, que é narrativo e histórico. Assim como em sua Historia Ecclesiastica, "os pontos que [Hobbes] quer articular são ou expostos e, então, exemplificados ou deduzidos das situações e eventos relatados" (LESSAY 2000, p. 151).

É importante enfatizar, porém, que Hobbes não estava raciocinando de ocorrência à ocorrência, de fato a fato. Sua interpretação do passado da Igreja cristã era de ponta a ponta informada por ideias articuladas demonstrativamente por sua ciência civil. Ao mesmo tempo, essas ideias ganhavam em visibilidade e poder persuasivo quando colocadas em um modo histórico. Creio, portanto, que a conclusão de Frank Lessay (2000, p. 153) a respeito do procedimento intelectual adotado tanto em Behemoth quanto na Historia Ecclesiastica, as duas outras histórias de Hobbes, é também válido aqui: "através de um dispositivo de mão dupla, as doutrinas conferem alguma medida de inteligibilidade à história, e a história dá maior visibilidade às doutrinas".

Logo, parece correto dizer, com Karl Schuhmann (2000, p. 10), que, para Hobbes, o filósofo é, afinal, o melhor historiador. Embora a história em si mesma (como res gestae) não tenha nenhum sentido intrínseco - de modo que uma filosofia ou teologia da história são inconcebíveis -, ela pode todavia ser tornada significativa pelo filósofo, que a interpreta de forma consciente com a ajuda de teorias, i.e., da perspectiva de "sistemas conceituais consistentes e bem definidos que não podem ser derivados das fontes, mas que tornam possíveis a identificação, exploração e explicação de objetos históricos" (KOCKA apud ANKERSMIT 1995, p. 158). Na história filosófica de Hobbes, a dinâmica temporal de instituições humanas, como a Igreja, o Estado, a linguagem e as leis, é explicada mediante recurso a um vocabulário conceitual estabelecido pela ciência civil hobbesiana, e essa explicação é modelada narrativamente de uma maneira calculada para produzir implicações normativas para o contexto de sua composição. É, portanto, significativo que a narração histórica de Hobbes conclua-se com uma denúncia estridente da "ferocidade" de clérigos e teólogos, "desde antes do Concílio de Niceia até o tempo presente", sempre prontos a vociferar "crucifique!" quando se sentem ofendidos em seu saber ou poder, ignorando tanto as leis quanto os preceitos evangélicos. Se, ao invés, ouvissem a admoestação de São Paulo, em 2 Timóteo 2: 24-25, ${ }^{14}$ e atentassem a história

\footnotetext{
13 Sem tradução direta para o português, o termo "priestcraft" é um neologismo do século XVII, criado para denunciar uma suposta tendência congênita do clero, em qualquer uma de suas roupagens, a corromper a religião em benefício próprio. Como tal, o conceito, senão o termo, foi empregado por autores de inclinações políticas díspares, tais como o republicano James Harrington (aparentemente, o primeiro a grafá-lo), John Locke e o próprio Hobbes. É tido como um dos elementos centrais responsáveis pela emergência da ideologia "Whig" no final do século (cf. GOLDIE 1993).

14 "[...] o servo do senhor não deve brigar; deve ser manso para com todos [...]. É com suavidade que deve educar os opositores, na expectativa de que Deus Ihes dará não só a conversão para o conhecimento da verdade, mas também retorno à sensatez" (citado em HOBBES EW IV, Narration; 1840, p. 407-408). Hobbes utiliza a versão autorizada do Rei Jaime, adotada pela Igreja Anglicana. Para o português, recorri à Bíblia de Jerusalém.
} 
da heresia e de suas leis, reconheceriam que a razão e a eloquência, e não a violência, são as armas legítimas e apropriadas para lidar com as "heresias", ou melhor, com as diferenças (inevitáveis) de "opinião" religiosa.

À guisa de conclusão podemos retormar a sugestão anterior de que as críticas de Hobbes à experiência e à história fossem, de algum modo, compatíveis com um alinhamento, talvez até mesmo sub-reptício, aos procedimentos eruditos da scholarship histórica contemporânea. Afinal, até que ponto a prática historiográfica tardia de Hobbes estava de acordo com o padrão de sua época? Se é verdadeiro que "escritores políticos do início do Época Moderna combinavam elementos históricos e teóricos de modo deveras impensado (quite unselfconsciously)" (SOMMERVILLE, 2000), usando ideas abstratas para iluminar a história e exemplos históricos para ilustrar alegações teóricas, em Hobbes a balança pende significativamente na direção da teoria. Embora as conclusões das suas histórias eclesiásticas sejam muito semelhantes àquelas de historiadores e eruditos renomados como Paolo Sarpi, John Selden, ou Roger Twysden, também erastianos como Hobbes, seu uso das ferramentas da crítica histórica-filológica parece bastante tímida se comparado ao desses autores. ${ }^{15}$ Ao passo que obras como o monumental De Synedriis (1750-55), de Selden, são repletas de notas de rodapé, citações e referências eruditas a manuscritos antigos e a scholars antigos e modernos, os textos de Hobbes, relativamente curtos para os padrões contemporâneos, são também pobres de semelhantes recursos. Hobbes ignora tópicos importantes, não usa notas, citações ou apêndices, e sua exegese bíblica, 10 como notado recentemente por Sommerville (2000, p. 179), é frequentemente perfunctória e da "variedade protestante antiguada", i.e., toma a Escritura literalmente, "ignorando contexto histórico e sutilezas linguísticas", afastando-se do sentido literal apenas quando esse diverge daquilo que a (sua) filosofia diz ser verdadeiro. Ao ler An Historical Narration, Historia Ecclesiastica, ou Behemoth, é difícil evitar a sensação de que "Hobbes encontrou na história o que a teoria já havia provado" (SOMMERVILLE 2000, p. 179).

\section{Referências bibliográficas}

ANKERSMIT, Frank. Historicism: An Attempt at Synthesis. History and Theory, v. 34, n. 3, p. 143-161, 1995.

BÍBLIA DE JERUSALÉM. São Paulo: Paulus, 2006.

CHAMPION, Justin. An Historical Narration Concerning Heresie: Thomas Hobbes, Thomas Barlow, and the Restoration Debate over 'heresy.' In: LOEWENSTEIN, David; MARSHALL, John (Org.). Heresy, Literature and Politics in Early Modern English Culture. Cambridge: Cambridge University Press, 2007, p. 221-253.

\footnotetext{
15 Embora não os cite (procedimento recorrente em sua obra), Hobbes provavelmente baseou seu relato nesses e em outros autores erastianos. Sobre Twysden, cf. Champion (1992, p. 93-94). Sobre Sarpi, cf. Wooton (1983) e Kainulainen (2014). Sobre Hobbes e Selden, cf. Sommerville (2000).
} 
The Pillars of Priestcraft Shaken: The Church of England and Its Enemies, 1660-1730. Cambridge; New York: Cambridge University Press, 1992.

DUARTE, João. O Progresso do Peregrino: Religião e Política na Gênese do Iluminismo Inglês. Curitiba: Prismas, 2017.

GOLDIE, Mark. Priestcraft and the Birth of Whiggism. In: SKINNER, Quentin; PHILLIPSON, Nicholas (Org.). Political Discourse in Early Modern Britain. Cambridge; New York: Cambridge University Press, 1993, p. 209231.

The Theory of Religious Intolerance in Restoration England. In: GRELL, Ole Peter; ISRAEL, Jonathan; TYACHE, Nicholas (Org.). From Persecution to Toleration: The Glorious Revolution and Religion in England. Oxford; New York: Clarendon Press; Oxford University Press, 1991, p. 331-368.

GOLDIE, Mark; HARRIS, Tim; SEAWARD, Paul (Org.). The Politics of Religion in Restoration England. Oxford; Cambridge: Basil Blackwell, 1990.

GOLDSMITH, M. M. Hobbes on Law. In: SORELL, Tom (Org.). The Cambridge Companion to Hobbes. Cambridge; New York: Cambridge University Press, 1996, p. 274-304.

GRAFTON, Anthony. What was History? The Art of History in Early Modern Europe. Cambridge: Cambridge University Press, 2007.

HARRIS, Tim. Politics under the Later Stuarts: Party Conflict in a Divided Society, 1660-1715. London; New York: Longman, 1993.

Restoration: Charles II and His Kingdoms, 1660-1685. London; New York: Allen Lane, 2005.

Revolution: The Great Crisis of the British Monarchy, 1685-1720. London; New York: Allen Lane, 2006.

HOBBES, Thomas. An Answer to Bishop Bramhall's Book, Called 'The Catching of the Leviathan.' In: MOLESWORTH, William (Org.). The English Works of Thomas Hobbes of Malmesbury. London: John Bohn, 1840, p. 279384. v. IV.

A Dialogue between a Philosopher and a Student of the Common Laws of England. In: MOLESWORTH, William (Org.). The English Works of Thomas Hobbes of Malmesbury. London: John Bohn, 1840, p. 1-160. v. VI.

. An Historical Narration Concerning Heresy, and the Punishment Thereof. In: MOLESWORTH, William (Org.). The English Works of Thomas Hobbes of Malmesbury. London: John Bohn, 1840, p. 385-408. v. IV.

Leviatã. Traduzido por João Paulo Monteiro e Maria Beatriz Nizza da Silva. São Paulo: Abril Cultural, 1983.

Leviathan. Ed. by J. C. A. Gaskin. Oxford: Oxford University Press, 1998. 
KELLEY, Donald. Foundations of Modern Historical Scholarship: Language, Law, and History in the French Renaissance. New York: Columbia University Press, 1970.

. Legal Humanism and the Sense of History. Studies in the Renaissance, v. 13, p. 184-199, 1966.

LESSAY, Franck. Hobbes and Sacred History. In: ROGERS, G. A. J.; SORELL, Tom (Org.). Hobbes and History. London ; New York: Routledge, 2000, p. $146-158$.

MALCOLM, Noel. A Summary Biography of Hobbes. In: SORELL, Tom (Org.). The Cambridge Companion to Hobbes. Cambridge; New York: Cambridge University Press, 1996, p. 13-44.

MARSHALL, John. Defining and Redefining Heresy up to Locke's Letters Concerning Toleration. In: LOEWENSTEIN, David (Org.). Heresy, Literature and Politics in Early Modern English Culture. Cambridge: Cambridge University Press, 2007, p. 254-281.

MINT, Samuel. Hobbes on the Law of Heresy: A New Manuscript. Journal of the History of Ideas, v. 29, n. 3, p. 409-414, 1968.

MOMIGLIANO, Arnaldo. As Raízes Clássicas da

pHistoriografia Moderna. Traduzido por Maria Beatriz Borba Florenzano.

\$2 Bauru: EDUSC, 2004.

MORRILL, John. The Religious Context of the English Civil War. Transactions of the Royal Historical Society, n. 34, p. 155-178, 1984.

POCOCK, J. G. A. The Ancient Constitution and the Feudal Law: A Study of English Historical Thought in the Seventeenth Century. Cambridge; New York: Cambridge University Press, 1987.

The Machiavellian Moment: Florentine Political Thought and the Atlantic Republican Tradition. $2^{\text {th }}$ ed. Princeton; Oxford: Princeton University Press, 2003.

. Time, History and Escathology in the Thought of Thomas Hobbes. In: . Politics, Language and Time: Essays on Political Thought and History. New York: Atheneum, 1971, p. 148-201.

SCOTT, Jonathan. England's Troubles: Exhuming the Popish Plot. In: HARRIS, Tim; SEAWARD, Paul; GOLDIE, Mark (Org.). The Politics of Religion in Restoration England. Oxford; Cambridge: Basil Blackwell, 1990.

SCHUHMANN, Karl. Hobbes's Concept of History. In: ROGERS, G. A. J.; SORELL, Tom (Org.). Hobbes and History. London; New York: Routledge, 2000, p. 3-23.

SKINNER, Quentin. Reason and Rhetoric in the Philosophy of Hobbes. Cambridge; New York: Cambridge University Press, 1996. 
SOMMERVILLE, John. Hobbes, Selden, Erastianism, and the History of the Jews. In: ROGERS, G. A. J.; SORELL, Tom (Org.). Hobbes and History. London; New York: Routledge, 2000, p. 159-187.

WILLMAN, Robert. Hobbes on the Law of Heresy. Journal of the History of Ideas, v. 31, n. 4, p. 607-613, 1970. 